\title{
MorfoloGía flORAL Y EMBRIOLOGÍA DE BEGONIA GRACILIS (BEGONIACEAE): SU RELEVANCIA EN LA MONOECIA
}

\author{
Elizabeth Chávez-García y Sonia Vázquez-Santana ${ }^{1}$ \\ Laboratorio de Desarrollo en Plantas. Departamento de Biología Comparada, \\ Facultad de Ciencias, Universidad Nacional Autónoma de México, México D.F. \\ 'Autor para la correspondencia: svs@ciencias.unam.mx
}

\begin{abstract}
Resumen: En este estudio se describe el desarrollo de las flores masculinas y femeninas de Begonia gracilis mediante técnicas convencionales de histología y microscopía. La finalidad fue determinar si se desarrolla sólo uno de los verticilos o las flores se inician como bisexuales y hay aborción posterior del androceo o del gineceo. Los resultados indican que la unisexualidad se establece desde el meristemo, ya que en ningún morfo floral aparecen órganos atrofiados. Las flores femeninas desarrollan un estilo que se trifurca en el ápice, terminando en tres estigmas secos, bilobulados, papilosos y enrollados helicoidalmente. El óvulo es crasinucelado, bitégmico y anátropo, con micrópilo anfístomo. Las flores masculinas desarrollan estambres libres y sin reminiscencias de gineceo. Las tétradas de microsporas son tetraédricas e isobilaterales. El grano de polen es bicelular y tricolporado, con exina estriada y verrugada-estriada cerca de las aberturas. Por lo tanto, los resultados permiten concluir que la unisexualidad en $B$. gracilis se establece desde el meristemo floral, posiblemente por mutaciones en aquellos genes homeóticos que regulan el desarrollo de los verticilos sexuales.
\end{abstract}

Palabras clave: Begonia, desarrollo floral, embriología, monoecia, unisexualidad.

\begin{abstract}
In this study the development of the male and female flowers of Begonia gracilis is described, using conventional histological and microscopic techniques. The aims were to clarify whether just one whorl is initiated on the meristem or if the flower begins as bisexual and later abortion occurs on androecium or gynoecium. The results show that the unisexuality is established in the floral meristem, because any floral morph develops atrophied organs. The female flowers develop a style that is trifurcate on the tip, forming three dry, bifid, papillate, and helically twisted stigmas. The ovule is crassinucellate, bitegmic and anatropous. The micropyle is amphistome. The male flowers develop free stamens and the gynoecium reminiscences are absent. The microspores tetrads are tetrahedric and isobilateral. The pollen grain is bicellular and tricolporate, with striate and verrugate-striate exine near to the apertures. Based on results we conclude that unisexuality in B. gracilis is established since the floral meristem, likely by mutations in homeotic genes that regulate the development of sexual whorls.
\end{abstract}

Key words: Begonia, embryology, floral development, monoecy, unisexuality.

$\mathbf{L}$ a monoecia, - caracterizada por la presencia de las flores unisexuales masculinas y femeninas dispuestas sobre un mismo individuo de la población (Font-Quer, 2001; Mitchell y Diggle, 2005; Orozco-Arroyo et al., 2009) - es un sistema sexual que ha evolucionado en el $7 \%$ de las angiospermas, siendo más común en monocotiledóneas (10\% de sus especies) que en dicotiledóneas (4\% de sus especies; Yampolsky y Yampolsky, 1922). Se considera que las especies monoicas están generalmente asociadas con polinización abiótica (Renner y Ricklefs, 1995). En el caso de Begonia rostrata y $B$. wallichiana y otras especies, las anteras de las flores masculinas están tan cerca que al liberarse el polen, éste cae directamente sobre los estigmas de las flores femeninas vecinas (Wilde, 2011). Sin embargo, también hay especies monoicas dependientes de polinizadores para el transporte de polen y pueden ser tanto autocompatibles como autoincompatibles (de Jong et al., 2008; Wilde, 2011). En los sistemas monoicos, generalmente las flores femeninas no ofrecen recompensa a sus visitantes y la polinización se realiza por engaño. Los animales involucrados en el movimiento del polen son atraídos porque los estigmas de las flores femeninas mimetizan a las anteras de las flores masculinas, siendo engañados y efectuándose el depósito del polen, pero sin recibir recompensa alguna (Dafni, 1984). Se ha demostrado que varias especies de Begonia utilizan este sistema de polinización. Entre menos discriminen los polinizado- 
res mayor será el número de visitas florales para mover los gametos de una manera más eficiente (Ågren y Schemske, 1991; Schemske et al., 1996; Le Corff et al., 1998; CastilloGámez, 1999; Castillo et al., 2002; Cozza, 2008).

Entre las características distintivas de la monoecia como sistema sexual se encuentran: (a) que favorece la polinización cruzada, (b) reduce la interferencia entre el polen y el estigma, (c) permite el control en el patrón de asignación sexual en ambientes variables y (d) permite el mantenimiento del sistema sexual en ambientes constantes (de Jong et al., 2008).

La familia Begoniaceae se constituye por tres géneros, Begonia, Hillebrandia y Symbegonia, los dos últimos representados por pocas especies, ya que la mayoría se encuentran incluidas en el género Begonia (Thompson y Thompson, 1981; Forrest et al., 2005; Calderón-de Rzedowski y Rzedowski, 2005; Dewitte et al., 2011). En algunos tratamientos taxonómicos Symbegonia forma parte de la sección Petermannia del género Begonia (Forrest y Hollingsworth, 2003), pero en otros más recientes sobre Begoniaceae, hay un consenso en reconocer para esta familia sólo dos géneros bien diferenciados, Hillebrandia de las Islas del Pacífico y Begonia. Este último con cerca de 1,500 especies arregladas en 63 secciones, las cuales al momento están poco definidas por carencia de filogenias y por ser el más diverso en caracteres (Wilde, 2011). Cabe señalar que el género Begonia se distribuye con 600 especies en América, 650 en Asia y 140 en África (Forrest y Hollingsworth, 2003; Dewitte et al., 2011). En México 74 especies (de 100 que existen) son endémicas y se localizan desde los estados del norte hasta la zona sur del país (Burt-Utley, 1990; Caballero-Quiroz, 2002).

Begonia gracilis pertenece a la sección Knesdeckia. Es una hierba perenne, con inflorescencias compuestas por flores masculinas y femeninas, de color rosa y sin aroma aparente al olfato humano (de Lange y Bouman, 1999; Rojo y Rodríguez, 2002; Calderón-de Rzedowski y Rzedowski, 2005). Las flores masculinas de B. gracilis producen polen como recompensa para los visitantes que incluyen abejas (Apis mellifera y Halictidae sp.), moscas (Syrphidae sp.) y mariposas (Lycaenidae sp., Castillo-Gámez, 1999). Esta especie puede alterar sus patrones de asignación sexual, en respuesta a las variaciones en los niveles de polinización, lo cual puede ocurrir por: (1) la diferenciación de un mayor número de meristemos florales de uno de los dos sexos o (2) por medio de la aborción en el meristemo floral de los primordios de los estambres o de los carpelos (López y Domínguez, 2003; López-Mendoza, 2004; Chávez-García, 2009). Pero no se sabe cómo ni cuándo se establece la unisexualidad, es por esto que consideramos necesario estudiar las fases de desarrollo que definan cuál es el patrón de desarrollo unisexual en $B$. gracilis, ya que en otras especies hay reminiscencias de uno de los verticilos sexuales. A pesar de que B. gracilis es autocompatible (Castillo-Gámez, 1999;
Castillo et al., 2002), el porcentaje de semillas formadas naturalmente es muy bajo, por lo que se indagó sobre la fertilidad de los óvulos y el polen. Debido a que existen controversias embriológicas para el género Begonia, este estudio también generó información morfológica y embriológica de B. gracilis que contribuye a resolver esta situación.

\section{Materiales y métodos}

Selección y fijación del material biológico. Se colectaron botones florales, flores en antesis y frutos de al menos 30 individuos de Begonia gracilis ubicados en la Reserva Ecológica del Pedregal de San Ángel (en el campus de la Universidad Nacional Autónoma de México, en la Ciudad de México). De cada individuo se recolectaron 8-10 frutos y flores de cada etapa de desarrollo, tanto masculinas como femeninas. Las flores y frutos fueron fijados en FAA (formol, ácido acético, etanol y agua 2:1:10:7). Se realizaron conteos de óvulos y estambres para conocer el número promedio que produce $B$. gracilis. El ejemplar de herbario se depositó en el Herbario de la Facultad de Ciencias de la Universidad Nacional Autónoma de México, bajo el número de FCME 132723.

Microscopía óptica. Las muestras se deshidrataron en una serie de etanoles graduales $(50 \%, 70 \%, 85 \%, 96 \%, 100 \%$ y $100 \%$ ), se incluyeron en LR-White o en Paraplast Plus y se obtuvieron cortes histológicos de uno y ocho $\mu \mathrm{m}$ de grosor, respectivamente, los cuales se tiñeron con azul de toluidina o safranina-verde rápido en metilcelosolve, para posteriormente ser montados con Entellan y observados con microscopía óptica. Algunos cortes histológicos fueron usados para realizar pruebas histoquímicas como: ácido peryódico y reactivo de Schiff para carbohidratos, azul negro de naftol para proteínas y vainillina al 10\% para taninos condensados (Johansen, 1940; O’Brien y McCully, 1981; Ruzin, 1999; López-Curto et al., 2005).

Microscopía electrónica de barrido. Algunas muestras después de ser fijadas en FAA se deshidrataron en etanoles graduales $(30 \%, 50 \%, 70 \%, 85 \%, 96 \%, 100 \%)$ se procesaron en una secadora de punto crítico con $\mathrm{CO}_{2}$, se cubrieron con oro y se observaron en un microscopio Hitachi S-2460N (Vázquez-Nin y Echeverría, 2000). También se acetolizaron granos de polen de anteras colectadas de flores en antesis maceradas en seco y a las cuales se les agregó anhídrido acético y ácido sulfúrico. El material se mantuvo en agitación continua entre 65 y $70{ }^{\circ} \mathrm{C}$ durante ocho minutos. Posteriormente, se centrifugó a 2,500 rpm durante 10 minutos con ácido acético concentrado. Se decantó y se lavó en agua para ser tamizado y concentrado por centrifugación. Los granos de polen se colocaron en portaobjetos y se montaron con gelatina glicerinada (Erdtman, 1943; López-Curto et al., 2005). 


\section{Resultados}

Morfología de la flor femenina. Todos los individuos de la población de Begonia gracilis analizados fueron monoicos, con inflorescencias compuestas por flores masculinas y flores femeninas, en antesis ambas de color rosa intenso y sin reminiscencias de ninguno de los verticilos opuestos (Figura 1A). Las flores femeninas están formadas por cinco tépalos ovados de diferente tamaño (Figura 1B). Las partes del perianto están fusionadas a lo largo del ovario ínfero (Figura 1C) y forman en la parte distal de éste un cuello estrecho, justo a la altura de la inserción de la base del estilo en el ovario, en cuyo ápice se trifurca para formar tres estilos independientes, donde cada uno termina en un estigma amarillo y bilobulado (Figura 1C, D). Cada lóbulo estigmático se encuentra enrollado de forma helicoidal y lleno de papilas, las cuales son abundantes, unicelulares y alargadas (Figura 1E-G).

El surgimiento y desarrollo de los estigmas tiene una secuencia compleja. Al inicio del desarrollo el estilo, formado por tres carpelos fusionados, se alarga ligeramente, pero en el ápice, cada carpelo se independiza en un estilo, de los cuales comienzan a surgir los primordios de los estigmas. Cada estigma se bifurca tempranamente doblándose sobre sí mismo, a la vez que sus extremos forman dos lóbulos, que se enrollan siempre hacia el centro de la flor (Figura 1H-J). En una vista frontal, se observa que uno de los lóbulos estigmáticos se enrolla en dirección a las manecillas del reloj y el otro lóbulo en sentido opuesto (Figura 1K-M). Los estilos se van alargando ligeramente, distinguiéndose la independencia de éstos a la altura en que se insertan los estigmas (Figura 1L, M), pero fusionados en una sola estructura en la inserción con el ovario (Figura 1D). Conforme avanza el desarrollo estilar, también es evidente la diferenciación tisular en los estigmas, ya que al terminarse su enrollamiento, surgen de la epidermis interna del carpelo las múltiples papilas estigmáticas unicelulares. Los estigmas son papilosos y de tipo seco, porque no se distingue secreción alguna al momento de la antesis (Figura 1F, G).

El ovario ínfero está conformado por tres lóculos; posee un ala mayor (prolongación lateral del carpelo), de tamaño variable y triangular, las otras dos alas de los otros carpelos son más pequeñas y redondeadas. Asimismo, se observa la presencia de numerosos tricomas glandulares pluricelulares en la epidermis externa. En cada lóculo hay una placenta axial y bilamelar a la que están unidos numerosos óvulos (Figura 1N). La morfología de los óvulos en desarrollo muestra el surgimiento de los primordios ovulares (Figura 1O), el inicio de la curvatura de cada óvulo, el poco alargamiento del funículo, el surgimiento del primordio del tegumento interno y del tegumento externo (Figura 1P), así como la elongación de este último (Figura 1Q) para cubrir al tegumento interno. Aunque en esta etapa el tegumento interno no ha cubierto a la nucela, lo cual ocurre después (Fi- gura 1R). El óvulo maduro es casi sésil, ya que el funículo es corto (Figura 1S). El micrópilo está formado por ambos tegumentos (Figura 1T).

Desarrollo del gineceo. Una vez que se cierran los carpelos para la formación del ovario, surge el primordio del estilo, el cual en su base será una sola estructura, pero se trifurca en la zona distal para formar tres estilos independientes; de cada uno de ellos surge un primordio de estigma (Figura 2A). Cada estigma comienza a bifurcarse y a diferenciarse de manera helicoidal (Figura 2B). El tejido de transmisión sale del centro de las placentas hacia la parte superior del ovario y penetra a la base del estilo y en el ápice se dirige hacia cada uno de los tres estilos independientes. Se observaron sustancias ergásticas taniníferas en algunas células de los estigmas y estilos en formación (Figura 2C). En el interior del ovario joven, la placenta se diferencia desde etapas muy tempranas y conforme los carpelos se cierran para formar un ovario trilocular, algunas de las células de la epidermis interna comienzan a secretar sustancias ergásticas taniníferas. Hay drusas en la pared del ovario y en la epidermis externa se observan tricomas en desarrollo. Las células de la protodermis y de la subprotodermis que corren a lo largo de la placenta comienzan a dividirse en varios planos, formando ligeras protuberancias (Figura 2D), de las cuales surgen los primordios de los óvulos, los cuales se distinguen por una protodermis y bajo ella se forma una célula arquesporial (Figura 2E). Los primordios de óvulos comienzan a curvarse y a partir de divisiones en la protodermis y subprotodermis surgen los primordios del tegumento interno y externo. Cada primordio de tegumento es biestratificado y aunque el tegumento interno es el primero en surgir, el tegumento externo crece rápidamente y cubre al tegumento interno. El número de óvulos promedio por ovario es de 10,872 ( \pm $830.3, \mathrm{n}=16$ ).

Megasporogénesis y megagametogénesis. La célula arquesporial se divide y forma a una célula parietal en posición subepidérmica y una célula madre de la megaspora (Figura 2F). Ocurre la meiosis en la célula madre de la megaspora formando una tétrada lineal de megasporas rodeada aún por la nucela (Figura 2G). La megaspora funcional es la calazal y entra en mitosis para iniciar la formación del saco embrionario tipo Polygonum, mientras que las tres microsporas restantes degeneran al mismo tiempo que la nucela (Figura 2H). Las dos mitosis posteriores (Figura 2I) para la formación del saco embrionario evidenciaron que éste es heptacelular y octanucleado. Se observaron las tres antípodas, las cuales son efímeras (Figura 2J), la célula central binucleada, la ovocélula y las dos sinérgidas en diferentes cortes histológicos.

Los tegumentos se distinguen claramente durante la diferenciación de la megaspora funcional, cuando el óvulo se curva completamente convirtiéndose en anátropo. El tegu- 

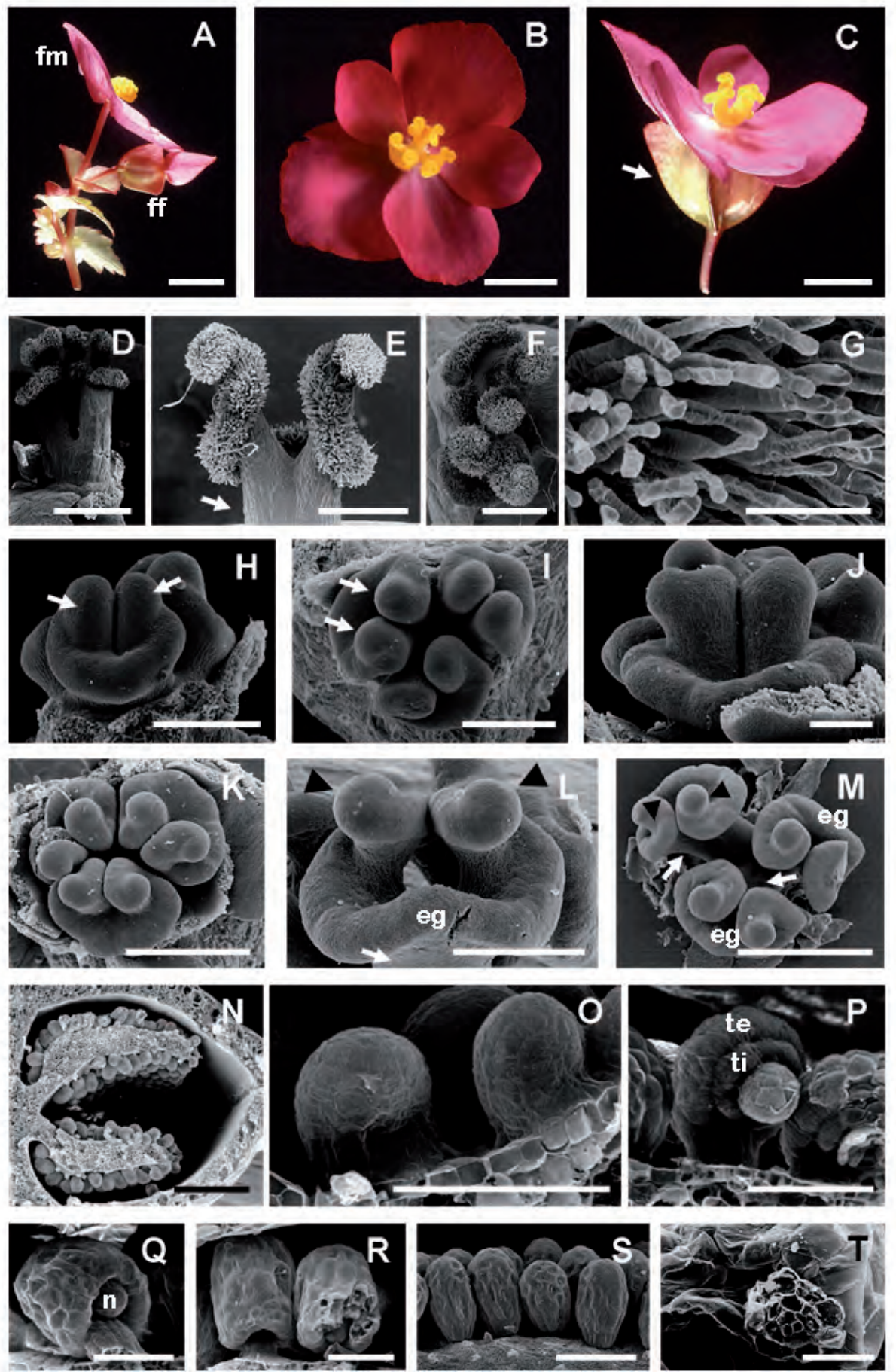

Figura 1. Inflorescencia y morfología de la flor femenina y óvulos. A, inflorescencia con flor masculina (fm) y femenina (ff). B, vista frontal de flor femenina. C, flor femenina mostrando el ovario ínfero (flecha). D, zona estilo-estigma, los estigmas maduros son bilobulados, el estilo es una sola estructura basal, pero en el ápice se trifurca. E, estigma y estilo (flecha) en vista lateral. F, dos de los tres estigmas maduros en vista frontal. G, papilas estigmáticas unicelulares. H-I, estigmas jóvenes en vista lateral y frontal respectivamente, iniciando la bifurcación de cada lóbulo (flechas). J-K, estado de desarrollo intermedio de los estilos y lóbulos estigmáticos enrollándose helicoidalmente, vistas lateral y frontal respectivamente. L-M, vista lateral y frontal respectivamente de los estigmas (eg) previos a la diferenciación de papilas, se observa la parte libre de cada estilo (flecha); cada lóbulo estigmático (cabeza de flecha) se enrollan helicoidalmente en sentido opuesto. $\mathbf{N}$, uno de los lóculos del ovario mostrando la placenta bilamelar. O, primordios de óvulos. $\mathbf{P}$, primordio del tegumento interno (ti) y externo (te). $\mathbf{Q}$, tegumento externo cubriendo al interno, pero no a la nucela (n). R, el tegumento externo ha cubierto al interno y a la nucela. S, óvulos maduros anátropos y casi sésiles. T, zona hilo-micrópilar de un óvulo maduro. Escalas: A-C = $1 \mathrm{~cm} ; \mathrm{D}, \mathrm{N}=2 \mathrm{~mm}$; E-F, $\mathrm{M}=1 \mathrm{~mm} ; \mathrm{G}, \mathrm{J}=100 \mu \mathrm{m} ; \mathrm{H}-\mathrm{I}, \mathrm{S}=200 \mu \mathrm{m} ; \mathrm{K}, \mathrm{L}=500 \mu \mathrm{m} ; \mathrm{O}-\mathrm{R}=50 \mu \mathrm{m} ; \mathrm{T}=20 \mu \mathrm{m}$. 

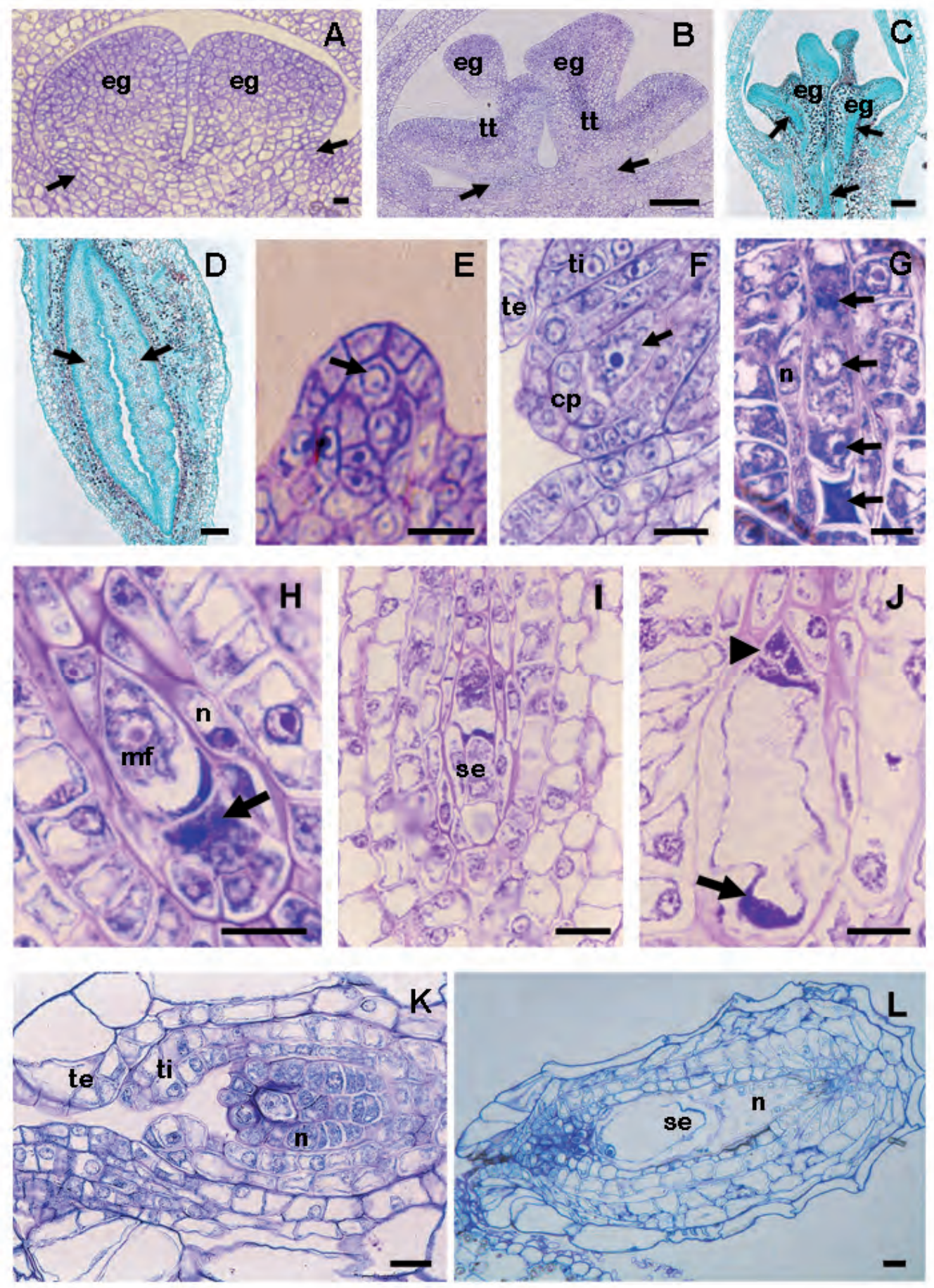

Figura 2. Desarrollo del gineceo y de los óvulos. A, corte longitudinal de botón floral femenino con primordios de estigmas (eg) y estilos (flechas). B, etapa intermedia de desarrollo de estigma (eg) y estilo (flechas), cuando surge el tejido de transmisión (tt) y los lóbulos estigmáticos (eg). C, corte longitudinal de botón floral cuyos estigmas (eg) y estilos muestran el tejido de transmisión (flechas) en diferenciación. D, lóculo del ovario con placenta (flechas) y taninos abundantes (puntos oscuros). E, primordio de óvulo con célula arquesporial (flecha) rodeada por una protodermis. F, óvulo cuya célula arquesporial se ha dividido mitóticamente en célula parietal (cp) y célula madre de la megaspora (flecha), también se observa el primordio del tegumento interno (ti) y del tegumento externo (te). G, tétrada lineal de megasporas (flechas) rodeada de nucela (n) en degeneración. H, megaspora funcional (mf) y degeneración de las tres microsporas micropilares (flecha); nucela (n) degenerando. I, saco embrionario en formación (se), algunos núcleos han migrado hacia la cálaza y otros hacia el micrópilo. J, saco embrionario maduro con ovocélula (flecha) y antípodas degenerando (cabeza de flecha). K, óvulo joven con tegumento interno (ti) y externo (te), rodeando a la nucela (n). L, óvulo maduro anátropo, bitégmico casi sésil, mostrando el saco embrionario (se) y la nucela (n). Escalas: A, E-L $=10 \mu \mathrm{m} ; \mathrm{B}, \mathrm{D}=100 \mu \mathrm{m} ; \mathrm{C}=200 \mu \mathrm{m}$. 
mento interno es biestratificado y rodea a la nucela, la cual se observa en degeneración. El tegumento externo es biestratificado en esta etapa, con la epidermis externa formada de células grandes y vacuoladas. El tegumento externo crece más que el interno, pero ambos van formando el micrópilo (Figura 2K). De acuerdo a los patrones de desarrollo, el óvulo maduro se describe como crasinucelado, anátropo y bitégmico, con el micrópilo formado por ambos tegumentos (anfístomo). Se observa un tapete tegumentario formado por la epidermis interna del tegumento interno, cuyas células se alargan radialmente con respecto al eje mayor del saco embrionario (Figura 2L).

Morfología de la flor masculina. En antesis consta de cuatro tépalos, a diferencia de los cinco de la flor femenina; aunque ambas flores son semejantes en forma y color, el tamaño difiere. En el caso de las flores masculinas, hay un verticilo de dos tépalos externos de mayor tamaño que los dos internos (Figura 3A). Los tépalos y los pedicelos presentan tricomas glandulares pluricelulares desde etapas tempranas (Figu- ra 3B), además de estomas (Figura 3C). El androceo está conformado en promedio por 28 estambres independientes $(27.7 \pm 3.3, \mathrm{n}=30)$ que surgen del centro del receptáculo (Figura 3D). En etapas tempranas del desarrollo los estambres se distribuyen en forma de racimo desde el centro del receptáculo; las anteras inicialmente son globosas y el filamento es corto (Figura 3E). Posteriormente, se observa una forma bilobulada y tetrasporangiada (Figura 3F). La parte dorsal de las anteras va creciendo y ensanchándose lateralmente, evidenciándose la línea de dehiscencia entre los dos microsporangios de cada lóbulo (Figura 3G). En etapa de antesis y dehiscencia de las anteras, los filamentos se observan alargados y libres, sobre ellos descansan las anteras globosas basifijas con una línea de dehiscencia longitudinal corta entre cada par de microsporangios que no llega a los extremos de éstos (Figura 3H). Los granos de polen se liberan en mónadas y son tricolporados, con ornamentación verrugada-estriada en la zona de las aberturas y con estrías paralelas a las aberturas en el resto de la pared del grano de polen (Figura 3I, J).
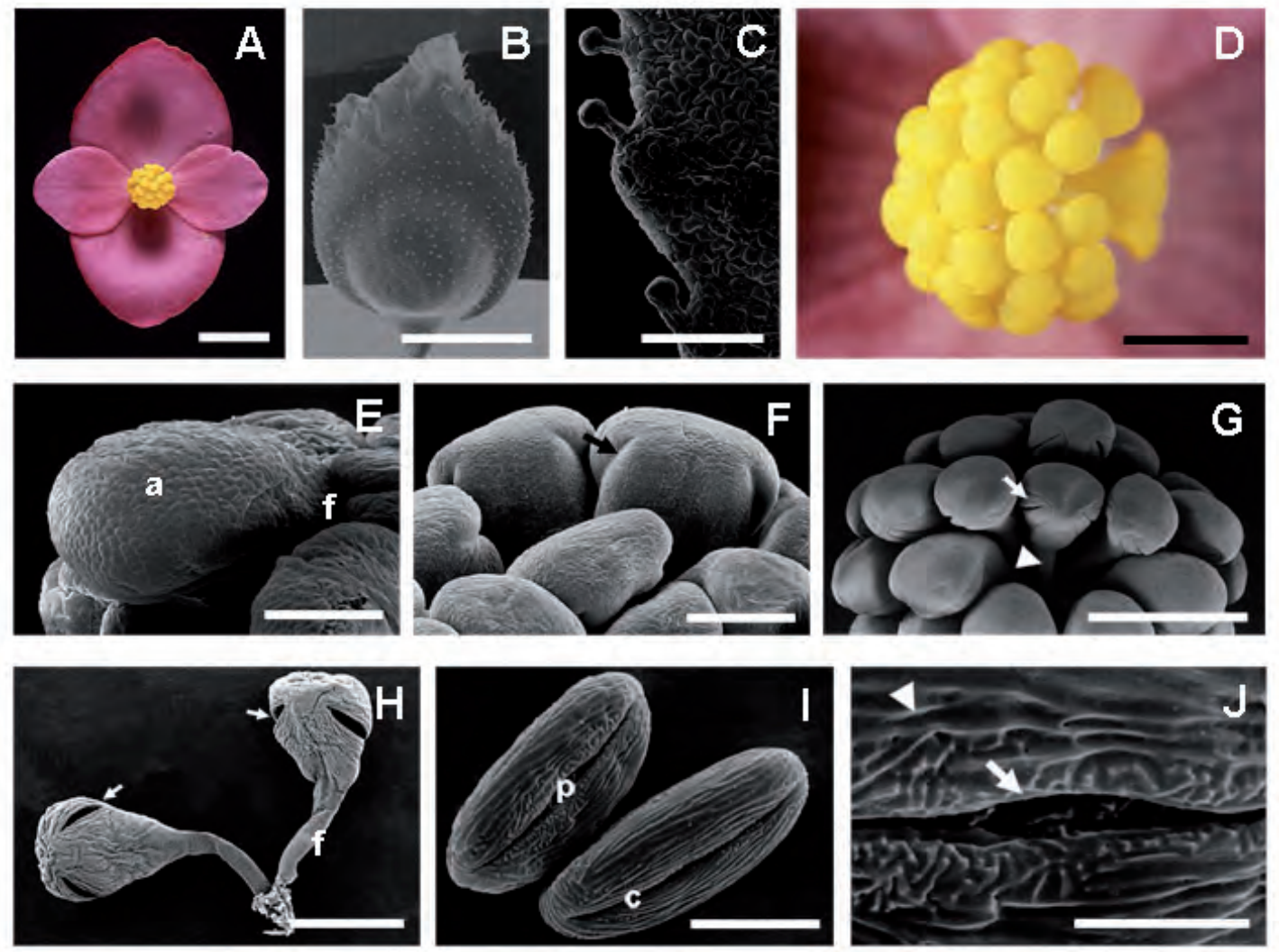

Figura 3. Morfología de la flor masculina, anteras y granos de polen. A, flor masculina en vista frontal con tépalos de diferente tamaño. B, botón floral masculino con tricomas en la epidermis abaxial de los tépalos. C, tépalo con tricomas y estomas en la superficie adaxial. D, acercamiento al androceo. E, estambres jóvenes con filamentos cortos (f) y anteras globosas (a). F, etapa intermedia del desarrollo de las anteras, con incipiente zona de dehiscencia (flecha). G, etapa madura del desarrollo de las anteras, con línea de dehiscencia evidente (flecha) y filamentos alargados (cabeza de flecha). H, anteras maduras con dehiscencia longitudinal (flechas) y filamento (f) alargado. I, vista ecuatorial de granos de polen maduros, mostrando un colpo (c) y un poro (p). J, acercamiento del colpo y del poro; la exina es verrugada-estriada (flecha) en la zona de las aberturas y estriada en el resto de la pared (cabeza de flecha). Escalas: A = 1 cm; B, D, G = 2 mm; $\mathrm{C}, \mathrm{F}=200 \mu \mathrm{m} ; \mathrm{E}=100 \mu \mathrm{m} ; \mathrm{H}=1 \mathrm{~mm} ; \mathrm{I}=10 \mu \mathrm{m} ; \mathrm{J}=4 \mu \mathrm{m}$. 
Desarrollo del androceo. En etapas tempranas del desarrollo de las flores masculinas, los estambres surgen de un receptáculo muy desarrollado, similar a un andróforo y con taninos. Los filamentos son cortos con respecto a los primordios de anteras. Rodeando al androceo se observan los dos verticilos de tépalos, insertos cada uno en un nivel diferente (Figura 4A). Las anteras tienen un tejido conectivo abundante, sobre todo en la parte dorsal, por lo que los microsporangios se desplazan ligeramente hacia la parte ventral. En cada microsporangio joven se observan células arquesporiales rodeadas por una protodermis (Figura 4B), las cuales se dividen periclinalmente diferenciándose en tejido esporógeno y capa parietal primaria en posición subepidérmica (Figura 4C).

Las células de la capa parietal primaria se dividen periclinalmente formando dos capas parietales secundarias, la externa e interna (Figura 4D). Ambas vuelven a dividirse, la parietal secundaria interna forma hacia el interior al tapete y un estrato de capa media; mientras que la parietal secundaria externa forma al endotecio (ubicada en posición subepidérmica) y otro estrato de capa media, por lo tanto el desarrollo de la pared de antera es de tipo básico (Figura 4E). Posteriormente, alguno de los estratos de la capa media se divide periclinalmente, de tal manera que la capa media es triestratificada (Figura 4F).

Microsporogénesis y microgametogénesis. El tejido esporógeno también prolifera y sus células se convierten en células madres de las microsporas (Figura 4F), cada una se rodea por una pared de calosa, pero manteniéndose en contacto por medio de puentes citoplásmicos. En esta etapa, la pared de la antera joven está formada por una epidermis, un endotecio, una capa media triestratificada, cuyo estrato más interno comienza a colapsarse y un tapete tipo secretor, con células alargadas radialmente con citoplasma denso (Figura 4G). Los núcleos de las células del tapete experimentan cariocinesis, de tal manera que son binucleadas o trinucleadas (Figura 4H). Las células madres de las microsporas entran a meiosis I, sin formación de paredes individuales, ya que éstas se forman al finalizar la meiosis II, por lo tanto la microsporogénesis es de tipo simultáneo. Las tétradas de microsporas son tetraédricas e isobilaterales rodeadas individualmente de su propia pared y en conjunto por una pared de calosa (Figura 4I).

Las microsporas (granos de polen jóvenes) se liberan de la tétrada hacia los amplios microsporangios, los cuales están muy cercanos uno de otro en cada lóbulo de la antera, ya que el septo, que contiene sustancias ergásticas, se va adelgazando y se va formando el estomio (línea de dehiscencia). En esta etapa la pared de la antera tiene una epidermis, un endotecio y un estrato de capa media, todas con granos de almidón, así como las células del tejido conectivo, las cuales además presentan drusas; las paredes de las células tapetales se van desintegrando para liberar su contenido (Figura 4J). Antes de la dehiscencia, la pared de la antera está formada por una delgada epidermis y un endotecio, cuyas células engrosan sus paredes celulares en forma de barra (Figura 4K).

$\mathrm{Al}$ momento de la dehiscencia las anteras tienen apariencia redondeada y son ligeramente curvas, el pequeño estomio se rompe pero sin exponer ampliamente los lóculos de la antera como normalmente ocurre en aquellas con dehiscencia longitudinal (Figura 4L). Los granos de polen son binucleados, con granos de almidón (Figura 4M) y tricolporados (Figura 4N). Ocasionalmente, en algunos microsporangios, se encontraron granos de polen germinados con tubos polínicos largos (Figura 4O).

Fecundación y desarrollo de la semilla. Los tubos polínicos llegan al ovario por el tejido de transmisión desde las papilas estigmáticas, estilos y placentas. Las células del tegumento interno funcionan como un obturador, se alargan hasta ponerse en contacto con la epidermis placentaria para permitir la entrada del tubo polínico al micrópilo (Figura 5A). Sólo un tubo polínico ingresa al micrópilo (fecundación porógama) y descarga en una de las sinérgidas para posteriormente efectuarse la doble fecundación, la otra sinérgida comienza a degenerar un poco antes (Figura 5B). Los núcleos polares se fusionan previamente a la fecundación, formando un núcleo presumiblemente diploide que se une con uno de los núcleos espermáticos del tubo polínico formando el núcleo primario triploide del endospermo, el cual sigue un patrón de desarrollo nuclear (Figura 5C); mientras que el cigoto entra en una etapa de letargo.

Después de varias cariocinesis en el endospermo, alrededor de cada núcleo se forma una pared celular, en un patrón casi centrípeto, ya que las primeras paredes del endospermo en formarse son las de la periferia y las del centro al final. Una vez que la capa más externa del endospermo se forma, sus células se dividen anticlinalmente para formar una capa de aleurona, mientras que el resto de las células del endospermo pueden seguirse dividiendo en varios planos. Las células endospérmicas tienen reservas de almidón (Figura 5D, E).

La primera división del cigoto es transversal, ocurriendo cuando el endospermo está formado por unos cuantos núcleos. Posteriormente, la célula apical, de las dos resultantes, se divide longitudinalmente y la basal transversalmente, como en un tipo de embriogénesis onagráceo. El desarrollo del embrión sigue un típico desarrollo de etapa globular (Figura 5D), de corazón y de torpedo (Figura 5F). El eje embrionario es ensanchado y los cotiledones son cortos. Hay reservas almidonosas y proteínicas en los cotiledones. El tegmen, proveniente del tegumento interno, inicialmente es biestratificado, pero después de la fecundación comienza a colapsarse y se degrada. En contraste, las células de los dos estratos de la testa comienzan a alargarse principalmente en sentido cálaza-micrópilo y a engrosar sus paredes celulares.

Morfología del fruto y de la semilla. El fruto de Begonia gracilis es una cápsula trilocular, con el estigma persistente 

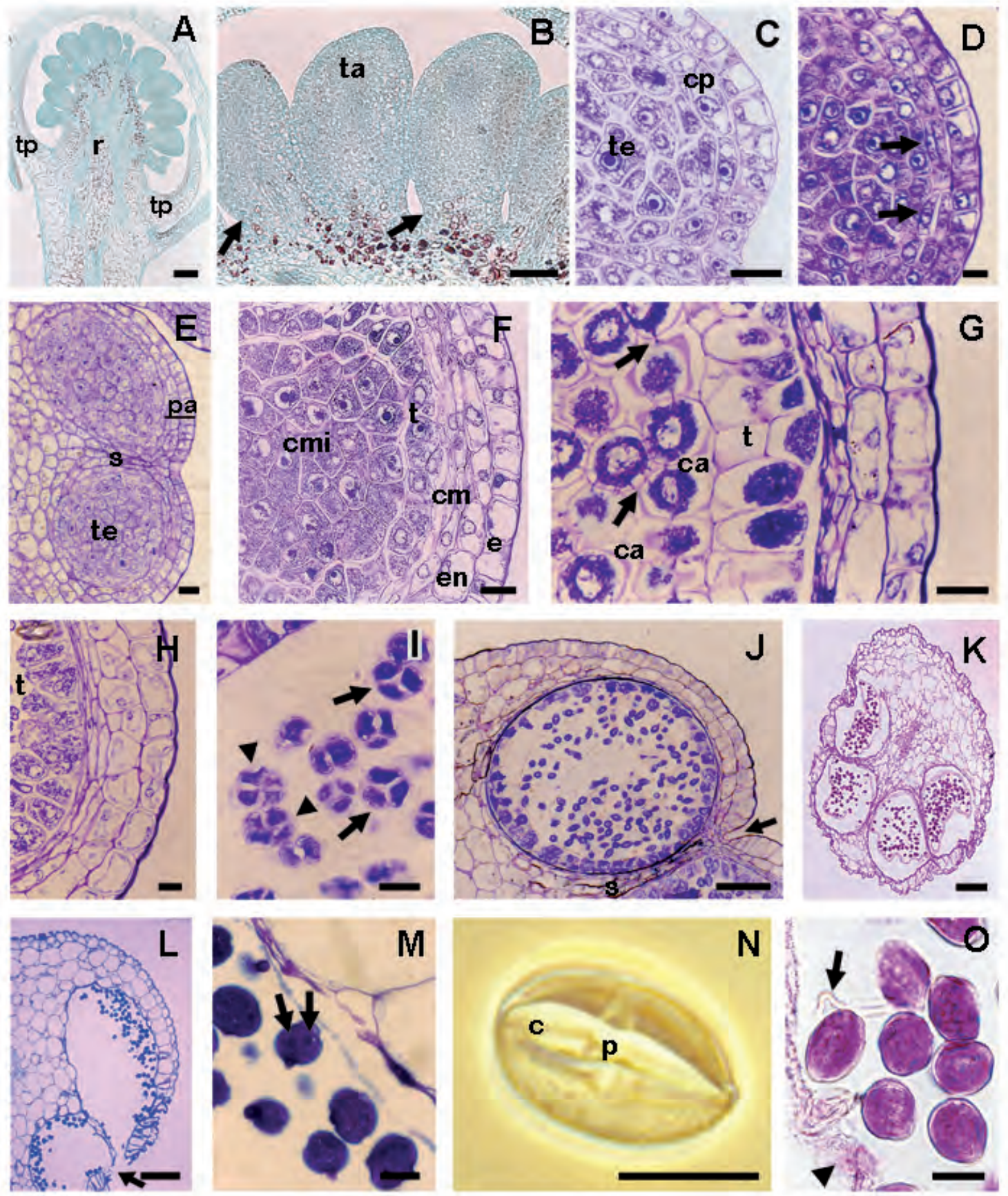

Figura 4. Desarrollo de las anteras y de los granos de polen. A, corte longitudinal de flor masculina con estambres desarrollándose sobre un receptáculo masivo (r) y con tépalos (tp). B, estambres jóvenes con anteras ensanchadas mostrando el tejido arquesporial (ta) y filamentos en diferenciación (flechas). C, microsporangio joven mostrando el tejido esporógeno (te) y la capa parietal primaria (cp). D, microsporangio donde se observan las divisiones periclinales de las células parietales secundarias (flechas). E, dos microsporangios divididos por un septo (s) y mostrando una pared de antera joven (pa) que rodea al tejido esporógeno (te). F, microsporangio con células madres de las microsporas $(\mathrm{cmi})$ rodeadas por un tapete $(\mathrm{t})$, dos a tres estratos de capa media $(\mathrm{cm})$, un endotecio $(\mathrm{en})$ y una epidermis (e). G, acercamiento a las células madres de las microsporas mostrando los puentes citoplasmáticos (flechas), la calosa que las rodea (ca) y un tapete (t) con células alargadas radialmente. $\mathbf{H}$, pared de antera en etapa intermedia mostrando el tapete secretor (t). I, tétradas de microsporas tetraédricas (flechas) e isobilaterales (cabezas de flecha) rodeadas de calosa. J, microsporas unicelulares liberadas de la tétrada; se observa el septo (s) y el estomio en formación (flecha). K, corte transversal de antera con tapete degenerando y septos adelgazados entre los microsporangios. L, dos microsporangios mostrando los granos de polen y la abertura del estomio (flecha). M, granos de polen bicelulares (flechas indicando los núcleos). $\mathbf{N}$, grano de polen acetolizado; se observa uno de los colpos (c) y uno de los poros (p). O, granos de polen germinados (flecha) dentro de un microsporangio de anteras aún cerradas. Escalas: A, E, K = $100 \mu \mathrm{m} ; \mathrm{B}, \mathrm{J}, \mathrm{L}=50 \mu \mathrm{m}$; C-D, F-I, M-O = $10 \mu \mathrm{m}$. 

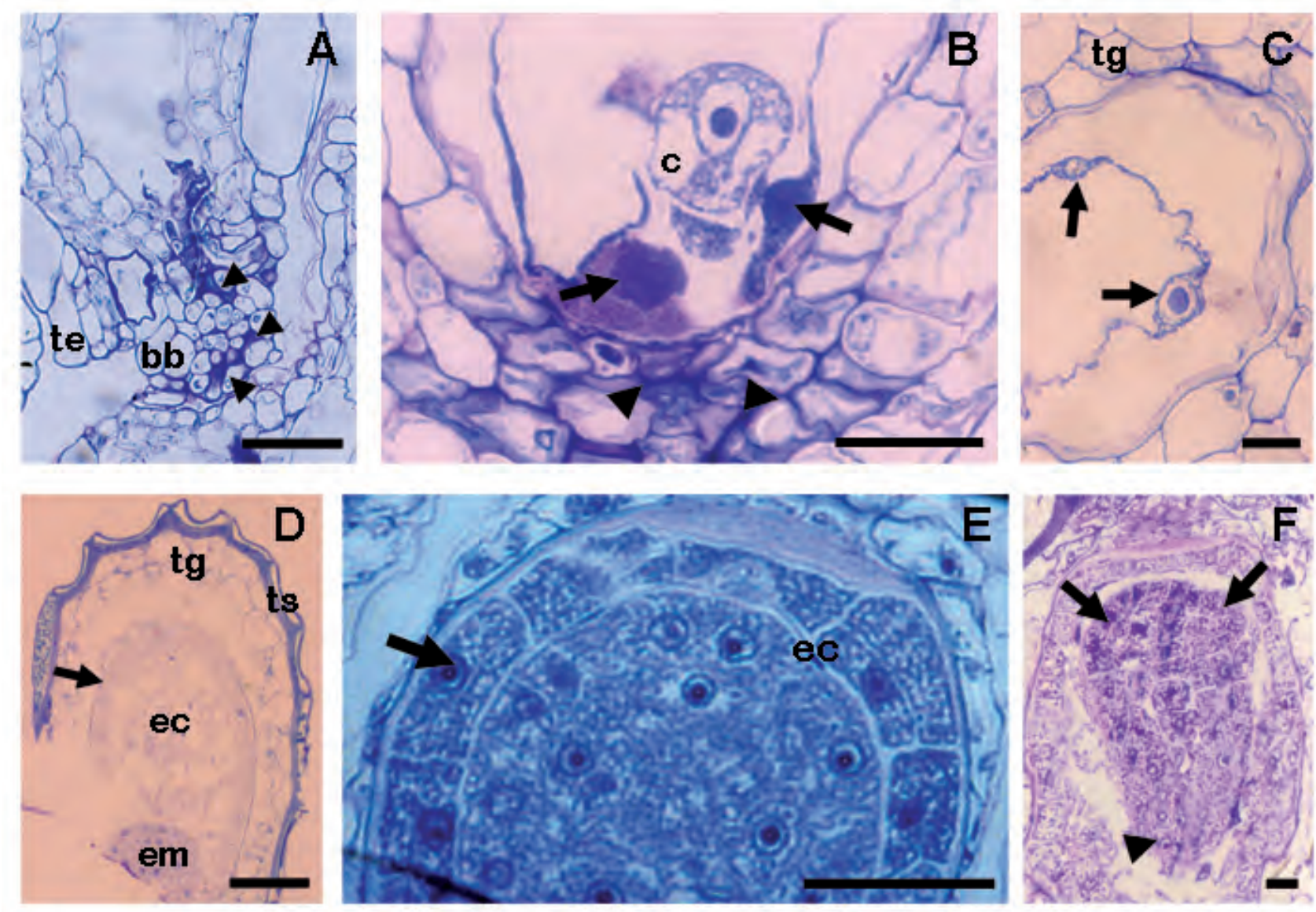

Figura 5. Desarrollo de la semilla. A, al momento de la fecundación, las células del tegumento interno sobresalen del tegumento externo (te) hasta la placenta, funcionando como obturador (bb); las cabezas de flechas indican la presencia de tubos polínicos. B, óvulo al momento de la fecundación, se observa el cigoto (c), las sinérgidas degenerando (flechas) y restos del tubo polínico (cabezas de flecha). C, endospermo nuclear (flechas); tegmen (tg) colapsándose. D, semilla mostrando el embrión globular (em), endospermo celular joven (ec), capa de aleurona en formación (flecha), tegmen (tg) y testa (ts) biestratificados. E, acercamiento al endospermo (ec) con la capa de aleurona (flecha). F, embrión de torpedo con su extremo radicular (cabeza de flecha) y los cotiledones (flechas). Escalas: A = $100 \mu$ m; B-C = $10 \mu \mathrm{m} ; \mathrm{D}=50 \mu \mathrm{m} ; \mathrm{E}=200 \mu \mathrm{m} ; \mathrm{F}=25 \mu \mathrm{m}$.

(Figura 6A, B). Los óvulos que no fueron fecundados abortan posteriormente y las semillas son de color café claro y ovoides (Figura 6C). En semillas jóvenes (antes de deshidratarse), las células de la exotesta inicialmente son globosas (Figura $6 \mathrm{D}-\mathrm{F})$, pero conforme la semilla madura éstas se deshidratan, de tal manera que las células de la exotesta son cóncavas (Figura 6G-I), con ornamentación rugoso-estriada (Figura 6J). Tienen un opérculo formado por las células de la exotesta en la región hilo-micropilar y un anillo de células del collar que son células alargadas en la exotesta, entre el opérculo y las células de la zona calazal. Este anillo ocupa casi un tercio de toda la cubierta seminal (Figura 6G). En semillas jóvenes, el exo- y endotegmen son uniestratificados y parenquimáti$\cos$, pero las paredes periclinales internas y las anticlinales de las células de la endotesta tienen engrosamiento secundario, siendo éste el estrato que da mayor rigidez a la semilla (semillas endotestales, Figura 6K). En etapa madura la semilla consta de una cubierta seminal biestratificada, formada por una exotesta parenquimática y una endotesta rígida cuyas paredes tienen engrosamientos secundarios (Figura 6L).

\section{Discusión}

En la presente investigación se demostró que la morfología floral y varios de los eventos embriológicos encontrados en Begonia gracilis coinciden con los de otras especies del género Begonia analizadas por diversos autores y que se encuentran concentrados en las publicaciones que describen a Begoniaceae y Begonia (Hall, 1949; Gauthier, 1950; Davis, 1966; Corner, 1976; Johri et al., 1992; Wilde, 2011). A pesar de que algunas características embriológicas y morfológicas son constantes para varias especies, no se puede generalizar para todo el género de Begonia, mucho menos para la familia Begoniaceae. Por ejemplo, se dice que el tipo de desarrollo de la pared de la antera es dicotiledóneo; sin embargo, en B. gracilis resultó ser de tipo básico. 

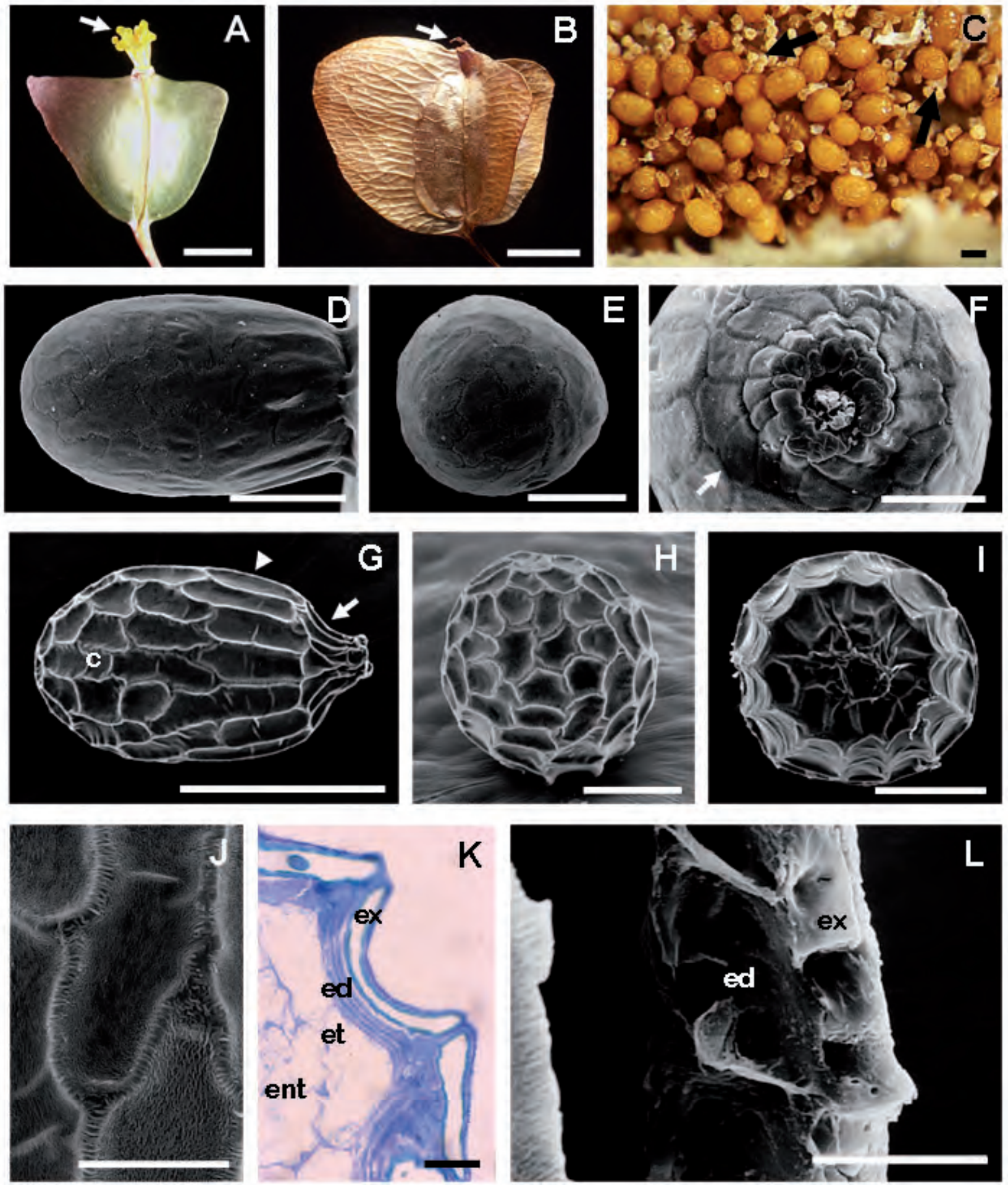

Figura 6. Morfología del fruto y de las semillas. A-B, frutos en vista lateral en etapa joven y madura respectivamente, mostrando la diferencia entre los tamaños de las alas y la persistencia del estigma (flechas). C, semillas maduras (de color café) y óvulos abortivos (flechas). D-F, semilla joven en vista lateral (D), calazal (E), micropilar (F) y la flecha señala el opérculo. G, semilla madura en vista lateral. Las células de la cálaza (c) son más cortas y redondeadas que las células alargadas del collar (cabeza de flecha) cercanas a las del opérculo (flecha). H, vista calazal. I, vista micropilar. J, acercamiento de la testa con ornamentación rugoso-estriada. K, corte de semilla joven mostrando la exotesta (ex), endotesta lignificándose (ed); el exotegmen (et) y endotegmen (ent) parenquimáticos. L, engrosamientos de la testa de semilla madura, se observa la exotesta (ex) y la endotesta (ed). Escalas: A-B = $1 \mathrm{~cm} ; \mathrm{C}-\mathrm{D}, \mathrm{F}, \mathrm{H}-\mathrm{I}=100 \mu \mathrm{m} ; \mathrm{E}=50 \mu \mathrm{m}$; $\mathrm{G}=200 \mu \mathrm{m} ; \mathrm{J}=40 \mu \mathrm{m} ; \mathrm{K}=10 \mu \mathrm{m} ; \mathrm{L}=20 \mu \mathrm{m}$. 
Swamy y Parameswaran (1960) mencionan que el tapete de las anteras de Begonia crenata es un tejido secretor binucleado y Davis (1966) generaliza estas característica para el género Begonia; sin embargo, nuestros datos en $B$. gracilis indican que tiene más de dos núcleos. Asimismo, Johri et al. (1992) señalan que el micrópilo se encuentra en zigzag para Begoniaceae, a diferencia de nuestras observaciones que revelan un micrópilo recto en $B$. gracilis y pone en evidencia que el tegumento interno protruye del micrópilo hacia la placenta durante la fecundación, funcionando de esta manera como un obturador, lo cual no había sido mencionado para ninguna otra especie de Begonia. Algunos autores mencionan la presencia de cristales de calcio como cistolitos en sépalos y pecíolos (Rose y Hurd-Karrer, 1927; Judd et al., 2002; Jacques y Mamede, 2005), pero en $B$. gracilis no se encontraron cistolitos en ninguna estructura floral, aunque sí drusas en el conectivo de las anteras y en la pared del ovario.

En todos los verticilos de Begonia gracilis se detectaron taninos condensados y en algunos casos almidón, los cuales han sido observados en los sépalos, las alas del ovario y el androceo de otras especies del género (Lecocq y Dumas, 1975; Lecocq, 1977; Judd et al., 2002). Matthews y Endress (2004) observaron que las células del tegumento externo del óvulo de $B$. incana tienen inclusiones de taninos en la zona calazal, en $B$. gracilis se encontraron células muy grandes con engrosamientos lignificados, pero no taninos.

Algunas de las características encontradas en Begonia gracilis, como el desarrollo del saco embrionario tipo Polygonum, el micrópilo anfístomo, la presencia de tapete tegumentario y de una capa de aleurona, la fusión de los núcleos polares previa a la fecundación, la meiosis simultánea y el polen bicelular, han sido mencionadas independientemente para ciertas especies de Begonia, pero no han sido exploradas en un mismo estudio (Swamy y Parameswaran, 1960; Davis, 1966; Maheswari-Devi et al., 1982; Johri et al., 1992; Matthews y Endress, 2004). Al parecer estos caracteres son constantes para el género Begonia. Una de las características embriológicas propuestas como de gran utilidad es el tipo de engrosamientos del endotecio, la capa subepidérmica de la antera relacionada con la dehiscencia. Esos engrosamientos son tan variables dentro de la familia que pueden ser utilizados para delimitar las secciones de Begonia (Tebbitt y Maciver, 1999), sin embargo faltan muchas especies por analizar. Cabe mencionar que en $B$. gracilis estos engrosamientos resultaron ser en forma de barra.

Hay quienes describen la presencia de placentas axiales y parietales para la familia Begoniaceae (Lecocq, 1977; Mathews y Endress, 2004). En este estudio se encontró que en Begonia gracilis la placentación es axial, la diferencia puede estar dada por el grado de expansión de la zona placentaria, por el número de carpelos involucrados o por el grado de fusión a lo largo del carpelo.

Entre la nueva información que aporta el presente estu- dio se encuentra la controversial ornamentación de la testa, nosotros consideramos que es del tipo rugoso-estriada y no granular como lo mencionan de Lange y Bouman (1999) para esta misma especie, lo cual, puede deberse a una malinterpretación de estos autores. Por otra parte, los estambres de Begonia gracilis no están unidos por la base como describe Castillo-Gámez (1999). Calderón-de Rzedowski y Rzedowski (2005) mencionan en la descripción del género Begonia que los estambres pueden estar unidos, pero no sucede así para $B$. gracilis. En nuestros resultados demostramos que cada antera tiene su propio filamento y surgen de un receptáculo pronunciado, similar a un andróforo si consideramos como definición botánica: "prolongación del eje floral que sostiene al androceo" (Font-Quer, 2001). Sin embargo, en algunas familias de angiospermas este término se utiliza para describir una estructura compleja, como es el caso de algunas especies de Triuris (Triuridaceae), donde el andróforo tiene prolongaciones laterales aladas y deltoides, en cuya base se insertan las anteras y hay cavidades secretoras (Ambrose et al., 2006), al igual que en el andróforo de Sterculia (Sterculiaceae, Mondragón, 2005). Si comparamos a $B$. gracilis con esas familias, los estambres no se encuentran insertos en ningún andróforo como tal, sino libres e independientes sobre un receptáculo prolongado, pero sin mayor diferenciación de tejidos.

Las capas medias no son efímeras como se generaliza para la familia Begoniaceae (Davis, 1966; Johri et al., 1992), ya que en Begonia gracilis persisten hasta que las microsporas se liberan de las tétradas. En $B$. gracilis se forman tétradas de microsporas tetraédricas y también isobilaterales, lo cual sólo había sido descrito para $B$. dichroa por Maheswari-Devi et al. (1982). En cuanto a la presencia de estilos, algunos autores no los mencionan o no dejan clara su existencia. Incluso algunos los confunden con estigmas (Davis, 1966; Hickey y King, 1981; Johri et al., 1992; Judd et al., 2002; Forrest et al., 2005). Sin embargo, sí se mencionan para B. tuberhybrida (Lecocq y Dumas, 1975; Lecocq, 1977), B. dregei (Charpentier et al., 1989), B. incana (Mathews y Endress, 2004) y B. pulvinifera (Peng et al., 2006). Suzuki y Hiura (1984) encuentran para $B$. semperflorens que dos de los estilos se encuentran fusionados y el tercero (y correspondiente al carpelo que forma el ala mayor del ovario) se encuentra libre. En el presente estudio se demuestra que en $B$. gracilis los carpelos en la base del estilo están fusionados formando una sola estructura, pero en el ápice se separan en tres y a partir de cada uno de estos estilos surge un estigma.

Con respecto a la formación de semillas, Castillo et al. (2002) mencionan que sólo el 8\% de las flores de Begonia gracilis forman frutos, lo cual sugiere que puede ocurrir un aborto post-fecundación, ya que en nuestras observaciones de frutos disectados bajo el microscopio estereoscópico, se detectaron muchos óvulos no fecundados (ver Figura 6C), pero no fueron cuantificados. Otra explicación posible dada 
por Castillo-Gámez (1999) y López y Domínguez (2003) es que los polinizadores no son del todo eficientes en el movimiento de polen, ya que cuando se realizan polinizaciones manuales, la producción de frutos aumenta considerablemente, hasta siete veces más. No obstante, nuestras observaciones registran una gran cantidad de tubos polínicos sobre la placenta y cerca del saco embrionario, lo cual sugiere que el número de tubos polínicos podría no ser la causa de la poca producción de semillas en $B$. gracilis. Sin embargo, se requiere de un análisis cuantitativo que demuestre si el número de tubos polínicos que llegan al ovario son suficientes para polinizar a los cientos de óvulos presentes en cada lóculo. Los resultados de polinizaciones manuales realizadas por Le Corff et al. (1998) en B. tonduzii y en B. urophylla, sugieren que la formación de los frutos en la naturaleza se puede ver afectada por la baja eficiencia de los polinizadores y lo comprobaron al realizar polinizaciones manuales, encontrando que la formación de frutos aumentó en más de un $28 \%$ en B. tonduzii y en un $9-13 \%$ en B. urophylla.

Los individuos de la población estudiada de Begonia gracilis han mostrado ser autocompatibles (Castillo-Gámez, 1999), lo que sugiere que la autogamia es un sistema de entrecruzamiento que ocurre con cierta frecuencia en esta especie. A pesar de ello, la reproducción cruzada (xenogamia) se ve favorecida por la conducta de sus polinizadores (abejas, moscas y mariposas), los cuales visitan generalmente sólo un morfo sexual antes de volar hacia otro individuo (Castillo-Gámez, 1999; Castillo et al., 2002). En algunas especies monoicas, como en $B$. gracilis, el tiempo de aparición de flores de uno u otro sexo no ocurre al mismo tiempo. Generalmente las de aparición temprana son las flores masculinas y las tardías son las femeninas, lo cual favorece la xenogamia. Se propone que en esta especie, algunos individuos producen sólo flores femeninas, como respuesta a un ambiente con abundante polen (producido por otros individuos), lo que sugiere que este tipo de influencia ambiental puede ser un factor básico para entender la evolución de los sistemas reproductivos en plantas (Harder et al., 2000), en particular en B. gracilis (Castillo-Gámez, 1999; Castillo et al., 2002; López y Domínguez, 2003).

Entre los muchos factores que pueden estudiarse para explicar la existencia de los sistemas monoicos, Cozza (2008) analizó la influencia del fotoperiodo y la disponibilidad de nutrimentos como el nitrógeno sobre plantas de Begonia urophylla, tratando de correlacionarlos con la expresión sexual. Entre otras cosas, él observó que la reducción del fotoperiodo induce la floración de esta especie. Asimismo, la disponibilidad de nitrógeno afecta el tamaño de la planta y la expresión sexual. Las plantas más grandes de B. urophylla producen más flores, sobre todo femeninas y por lo tanto también se ve favorecida la producción de frutos y semillas, pero los estudios sobre estos tópicos siguen siendo escasos en las especies de Begonia.

En este estudio se demostró que en Begonia gracilis la unisexualidad se presenta desde el inicio del meristemo floral, ya que después de que surgen los primordios de los tépalos, el meristemo floral se consume para dar origen a los estambres (en el caso de las flores masculinas) o carpelos (en el caso de las flores femeninas). Lo anterior corresponde a un tipo de desarrollo de flores unisexuales "por supresión" de acuerdo a la clasificación propuesta por Mitchell y Diggle (2005) para otras angiospermas y representa un patrón de desarrollo poco frecuente en las angiospermas. El patrón de desarrollo floral unisexual alternativo propuesto también por estos autores implica que el meristemo floral se inicia como bisexual y después, "por aborto" de uno de los dos verticilos sexuales (en alguna etapa de su desarro1lo), sólo quedan reminiscencias del verticilo abortado. No se descarta que este segundo patrón de desarrollo pudiera estar operando en algunas especies del género Begonia donde existen ambos verticilos sexuales en una misma flor, aunque uno generalmente se encuentre atrofiado, como en B. semperflorens, B. semperflorens var. gigantea, B. tuberhybrida e incluso en Hillebrandia sandwicensis (Dümmer, 1912; Matzke, 1938; Lecocq y Dumas, 1975; Matthews y Endress, 2004). Con respecto a B. semperflorens, Suzuki y Hiura (1984) encuentran que además de las flores unisexuales masculinas y femeninas, hay flores bisexuales anómalas. Al describir la morfología encuentran que varios óvulos están expuestos debido a que los carpelos no se cierran completamente y por tanto no serían fértiles. Sin embargo, no queda claro el por qué de la presencia de estos tipos florales con ambos sexos. Cozza (2008) también registró fenotipos hermafroditas en plantas de B. urophylla. En uno de estos individuos se observaron anteras y estigmas y el ovario poco desarrollado. Wilde (2011) menciona que a excepción de flores aberrantes, las flores pistiladas no contienen rudimentos de estambres. Lo anterior puede entenderse como la aceptación general de que la presencia de los dos sexos en una misma flor de Begonia debería interpretarse como eventos esporádicos y no como una confirmación de hermafroditismo.

La situación floral unisexual en los sistemas monoicos podría ocurrir por alguna alteración en la cascada de regulación asociada a la vía de diferenciación controlada por genes homeóticos que determinan la identidad de los verticilos sexuales (Coen y Meyerowitz, 1991). Debido a que cada individuo de Begonia gracilis tiene la capacidad genética de formar tanto flores masculinas como femeninas, esto sugiere que los genes homeóticos estarían bajo un control epigenético, el cual estaría silenciando a los genes homeóticos que disparan el desarrollo del gineceo en las flores masculinas y del androceo en las femeninas. Un ejemplo de esto sucede en Cucumis melo, una especie monoica donde la expresión del factor de transcripción $C m W I P 1$, lleva a la aborción de los carpelos dando origen a flores masculinas. En esta especie, el promotor de $C m W I P 1$ se encuentra silenciado por un mecanismo epigenético que resulta en la formación de flo- 
res femeninas en líneas ginodioicas (Martin et al., 2009).

Basados en nuestros resultados consideramos que en el futuro, las investigaciones en Begonia gracilis podrían dirigirse a estudiar como es el control genético involucrado en la diferenciación de flores masculinas y femeninas, así como en entender la baja eficiencia en la producción de semillas a pesar de que los granos de polen y óvulos que se forman son muchos.

\section{Agradecimientos}

Los autores agradecen a Susana Valencia Ávalos y Felipe Cruz García por la revisión del manuscrito, a Ma. Berenit Mendoza Garfias por la toma de microfotografías en el microscopio electrónico de barrido, a Ana Isabel Bieler y Alejandro Martínez Mena por la toma de fotomicrografías. A Margarita Ponce Salazar†, Mónica Karina Pérez Pacheco y Ricardo Wong por su asesoría técnica durante la realización de este trabajo. A Martha Martínez Gordillo por su apoyo en la elaboración del ejemplar de herbario. El financiamiento para esta investigación fue otorgado por la Facultad de Ciencias, UNAM y el Proyecto CONACYT 101771.

\section{Literatura citada}

Ågren J. y Schemske D.W. 1991. Pollination by deceit in a Neotropical monoecious herb, Begonia involucrata. Biotropica 23:235-241.

Ambrose B., Espinosa-Matías S., Vázquez-Santana S., VergaraSilva F., Martínez E., Márquez-Guzmán J. y Alvarez-Buylla E.R. 2006. Comparative developmental series of the Mexican triurids support a euanthial interpretation for the unusual reproductive axes of Lacandonia schismatica (Triuridaceae). American Journal of Botany 93:15-35.

Burt-Utley K. 1990. New and noteworthy species in Begonia section Gireoudia (Begoniaceae) from Mexico. Brittonia 42:38-46.

Caballero-Quiroz A.H. 2002. El papel del mimetismo floral en la polinización por engaño: un estudio experimental en Begonia gracilis HBK (Begoniaceae). Tesis de Licenciatura, Facultad de Ciencias, Universidad Nacional Autónoma de México, México, D.F. 36 pp.

Calderón-de Rzedowski G. y Rzedowski J. 2005. Flora Fanerogámica del Valle de México. Instituto de Ecología A.C./Comisión Nacional para el Conocimiento y Uso de la Biodiversidad, Pátzcuaro.

Castillo-Gámez R.A. 1999. Selección dependiente de la frecuencia en plantas: polinización por engaño en Begonia gracilis HBK (Begoniaceae). Tesis Doctoral, Instituto de Ecología, Universidad Nacional Autónoma de México, México, D.F. 95 pp.

Castillo R.A., Cordero C. y Domínguez C.A. 2002. Are reward polymorphisms subject to frequency- and density-dependent selection? Evidence from a monoecious species pollinated by deceit. Journal of Evolutionary Biology 15:544-552.

Charpentier A., Brouillet L. y Barabé D. 1989. Organogénèse de la fleur pistillée du Begonia dregei et de l'Hillebrandia sandwicensis (Begoniaceae). Canadian Journal of Botany 67:3625-3639.

Chávez-García E. 2009. Desarrollo floral y embriológico de Bego- nia gracilis HBK (Begoniaceae). Tesis de Licenciatura, Facultad de Ciencias, Universidad Nacional Autónoma de México, México, D.F. 73 pp.

Coen E.S. y Meyerowitz E.M. 1991. The war of the whorls: genetic interactions controlling flower development. Nature 353:31-37.

Corner E.J.H. 1976. The Seeds of Dicotyledons. Volume 1. Cambrigde University Press, Londres.

Cozza J. 2008. Sex expression in a rainforest understory herb, $B e$ gonia urophylla. PhD. Dissertation. University of Miami, Florida. $117 \mathrm{pp}$.

Dafni A.1984. Mimicry and deception in pollination. Annual Review of Ecology and Systematics 15:259-278.

Davis G.L. 1966. Systematic Embryology of Angiosperms. Jonh Wiley and Sons, Nueva York.

de Jong T.J., Shmida A. y Thuijsman F. 2008. Sex allocation in plants and the evolution of monoecy. Evolutionary Ecology Research 10:1087-1109.

de Lange A. y Bouman F. 1999. Seed micromorphology of neotropical begonias. Smithsonian Contributions to Botany 90:1-49.

Dewitte A., Twyford A.D., Thomas D.C., Kidner C.A. y Van Huylenbroeck J. 2011. The origin of diversity in Begonia: genome dynamism, population processes and phylogenetic patterns. En: Grillo O. y Venora G. Eds. The Dynamical Processes of Biodiversity - Case Studies of Evolution and Spatial Distribution, pp. 27-52, InTech, Rijeka.

Dümmer R.A. 1912. A bisexual "gymnospermous" Begonia. Annals of Botany os-26:1123-1124.

Erdtman G. 1943. An Introduction to Pollen Analysis. Chronica Botanica Company, Waltham.

Font-Quer P. 2001. Diccionario de Botánica. Ediciones Península, Barcelona.

Forrest L.L. y Hollingsworth P.M. 2003. A recircumscription of Begonia based on nuclear ribosomal sequences. Plant Systematics and Evolution 241:193-211.

Forrest L.L., Hughes M. y Hollingsworth P.M. 2005. A phylogeny of Begonia using nuclear ribosomal sequence data and morphological characters. Systematic Botany 30:671-682.

Gauthier R. 1950. The nature of the inferior ovary in the genus Begonia. Contributions de l'Institut de Botanique, Université de Montréal 66:1-93.

Hall B.A. 1949. The floral anatomy of Drosera and Begonia and its bearing on the theory of carpel polymorphism. American Journal of Botany 36:416-421.

Harder L.D., Barrett S.C.H. y Cole W.W. 2000. The mating consequences of sexual segregation within inflorescences of flowering plants. Proceedings of the Royal Society of London Series B-Biological Sciences 267:315-320.

Hickey M. y King C. 1981. 100 Families of Flowering Plants. Cambridge University Press, Nueva York.

Jacques E.L. y Mamede M.C.H. 2005. Notas nomenclaturais em Begonia L. (Begoniaceae). Revista Brasileira de Botânica 28:579-588.

Johansen D.A. 1940. Plant Microtechnique. McGraw-Hill Book Company, Nueva York.

Johri B.M., Ambegaokar K.B. y Srivastana P.S. 1992. Comparative Embryology of Angiosperms. Vol 1. Springer-Verlag, Nueva York.

Judd W.S., Campbell C.S., Kellogg E.A., Stevens P.F. y Donoghue M.J. 2002. Plant Systematics. A Phylogenetic Approach. Sin- 
auer Associates, Sunderland.

Lecocq M. y Dumas C. 1975. Histophysiologie des stigmates et des formations stigmatoïdes chez Begonia tuberhybrida. I. Observations préliminaires. Canadian Journal of Botany 53:1252-1258.

Lecocq M. 1977. Le gynécée du Begonia tuberhybrida et ses variations. Canadian Journal of Botany 55:525-541.

Le Corff J., Ågren J. y Schemske D.W. 1998. Floral display, pollinator discrimination, and female reproductive success in two monoecious Begonia species. Ecology 79:1610-1619.

López S. y Domínguez C.A. 2003. Sex choice in plants: facultative adjustment of the sex ratio in the perennial herb Begonia gracilis. Journal of Evolutionary Biology 16:1177-1185.

López-Mendoza S. 2004. La evolución en los ajustes facultativos en la proporción sexual en plantas: un estudio con Begonia gracilis. Tesis Doctoral, Instituto de Ecología, Universidad Nacional Autónoma de México, México, D.F. 114 pp.

López-Curto. M.L., Márquez-Guzmán J. y Murguía-Sánchez G. 2005. Técnicas para el Estudio del Desarrollo en Angiospermas. Universidad Nacional Autónoma de México/Facultad de Ciencias, México, D.F.

Maheswari-Devi H., Naidu K.C., Lakshmi V.A. y Manorama K. 1982. Male and female gametophytes in Begonia dichroa. Phytologia 51:299-301.

Martin A., Troadec C., Boualem A., Rajab M., Fernandez R., Morin H., Pitrat M., Dogimont C. y Bendahmane A. 2009. A transposon-induced epigenetic change leads to sex determination in melon. Nature 461:1135-1138.

Matthews M.L. y Endress P.K. 2004. Comparative floral structure and systematics in Cucurbitales (Corynocarpaceae, Coriariaceae, Tetramelaceae, Datiscaceae, Begoniaceae, Cucurbitaceae, Anisophylleaceae). Botanical Journal of the Linnean Society 145:129-185.

Matzke E.B. 1938. Inflorescence patterns and sexual expression in Begonia semperflorens. American Journal of Botany 25:465-478.

Mitchell C.H. y Diggle P.K. 2005. The evolution of unisexual flowers: morphological and functional convergence results from diverse developmental transitions. American Journal of Botany 92:1068-1076.

Mondragón A. 2005. Tres nuevas especies de Sterculia L. (Sterculiaceae) de Venezuela. Acta Botánica Venezuelica 28:135-144.

O’Brien T.P. y McCully M.E. 1981. The Study of Plant Structure: Principles and Selected Methods. Termarcarphi Pty Ltd, Melbourne.

Recibido: 14 de enero de 2012

Aceptado: 21 de mayo de 2012
Orozco-Arroyo G., Cruz-García F y Vázquez-Santana S. 2009. Understanding the genetic control on plant unisexuality. En: Gamboa-deBuen A., Orozco-Segovia A. y Cruz-García F. Eds. Functional Diversity of Plant Reproduction, pp. 47-78, Research Signpost, Keralia.

Peng C.I., Leong W.C., Ku S.M. y Liu Y. 2006. Begonia pulvinifera (sect. Diploclinium, Begoniaceae), a new species from limestone areas in Guangxi, China. Botanical Studies 47:319-327.

Renner S.S. y Ricklefs R.E. 1995. Dioecy and its correlates in the flowering plants. American Journal of Botany 82: 596-606.

Rojo A. y Rodríguez J. 2002. La Flora del Pedregal de San Ángel. Secretaría de Medio Ambiente y Recursos Naturales/Instituto Nacional de Ecología. México, D.F.

Rose D.H. y Hurd-Karrer A.M. 1927. Differential staining of specialized cells in Begonia with indicators. Plant Physiology 2:441-453.

Ruzin S.E. 1999. Plant Microtechnique and Microscopy. Oxford University Press, Oxford.

Schemske D.W., Ågren J. y Le Corff J. 1996. Deceit pollination in the monoecious, neotropical herb Begonia oaxacana (Begoniaceae). En: Lloyd D.G. y Barrett S.C.H. Eds. Floral Biology: Studies on Floral Evolution in Animal-Pollinated Plants, pp. 292-318, Chapman \& Hall, NuevaYork.

Suzuki H. y Hiura I. 1984. Sex differentiation in Begonia semperflorens I. Inflorescence and comparative anatomy of male and female flower. Japanese Journal of Breeding 34:87-99.

Swamy B.G.L. y Parameswaran N. 1960. A contribution to the embryology of Begonia crenata. Journal of the Indian Botanical Society 39:140-148.

Tebbitt M.C. y Maciver C.M. 1999. The systematic significance of the endothecium in Begoniaceae. Botanical Journal of the Linnean Society 131:203-221.

Thompson M.L. y Thompson E.J. 1981. Begonias: The Complete Reference Guide. Times Books, Nueva York.

Vázquez-Nin G. y Echeverría O. 2000. Introducción a la Microscopía Electrónica Aplicada a las Ciencias Biológicas. Universidad Nacional Autónoma de México/Fondo de Cultura Económica, México, D.F.

Wilde J.J.F.E. de. 2011. Begoniaceae. En: Kubitski K. Ed. The Families and Genera of Flowering Plants, Volume X. Flowering Plants Eudicots: Sapindales, Cucurbitales, Myrtaceae, pp. 5671, Springer Verlag, Berlín.

Yampolsky C. y Yampolsky H. 1922. Distribution of Sex Forms in the Phanerogamic Flora. Gebrüder Borntraeger, Leipzig. 